\title{
Argumentation, Rationality, and Psychology of Reasoning
}

\section{DAVID GODDEN}

\author{
Philosophy Department \\ Old Dominion University \\ Norfolk, Virginia 23529 \\ USA \\ dgodden@odu.edu \\ www.davidgodden.ca
}

\begin{abstract}
This paper locates a common picture of argumentative rationality and identifies some implicit assumptions. Argumentative rationality is contrasted with dualprocess theories of reasoning and rationality prevalent in the psychology of reasoning. I argue that argumentative rationality properly corresponds only with system-2 reasoning in dual-process theories. This challenges the prescriptive force of argumentative norms, if they derive from their descriptive accuracy of our cognitive processes. As a remedy, I propose an activity-based account of reasoning that retains the assumptions of argumentative rationality while recontextualizing the relationship between reasoning as a justificatory activity and the psychological states and processes underlying it.
\end{abstract}

Résumé: On identifie une idée commune et fondamentale de la nature de la rationalité argumentative et une collection d'hypothèses implicites en elle. Ensuite on met en contraste la rationalité argumentative avec les théories de double processus de raisonnement et de la rationalité qui prévalent dans la psychologie du raisonnement. On soutient que la rationalité argumentative correspond bien seulement avec un système-2 de raisonnement dans les théories de double processus. Ce résultat remet en cause la force normative des normes argumentatives, si elles proviennent du tout de leur exactitude descriptive de nos processus cognitifs. Comme un remède, je propose une explication fondée sur l'activité de raisonnement qui retient les suppositions de la rationalité argumentative tout en re-contextualisant la relation entre le raisonnement comme une activité de justification et les états et les processus psychologiques qui sous-tendent cette activité.

Keywords: argumentation, argumentative rationality, basing relations, bounded rationality, dual-process theory, justification, psychology of reasoning, rationality, reasoning, spectatorial conception

\section{Introduction}

Charles Willard (1989, p. 152) once observed that "Not all rationality theories include argument in their definitions, but vir-

(C) David Godden. Informal Logic, Vol. 35, No. 2 (2015), pp. 135-166. 


\section{David Godden}

tually all argument theories include rationality in theirs." ${ }^{1} \mathrm{Re}-$ gardless of their methodological or theoretical approach to argument, whether rhetorical, dialectical or epistemic, virtually all theories take rationality as the basic evaluative ideal of argument and suppose, either implicitly or explicitly, some theory of reasonableness or rationality. ${ }^{2}$ Johnson's $(2000$, p. 1) Manifest Rationality, for example, rejects Habermas's (1981, p. 22) suggestion that "the concept of rationality... has to be elucidated in terms of a theory of argumentation," claiming instead that "if the practice of argumentation is to be understood, it must be understood in terms of rationality." Correspondingly, Biro and Siegel claim that arguments, viewed normatively, are conceptually connected to rationality because "an argument succeeds to the extent that it renders belief rational" (1997, p. 278) and "the intrinsic goal of arguments is to provide reasons for belief" (2006, p. 94). Similarly, Pragma-Dialectics holds that "the evaluation of validity is put in the hands of a 'rational critic who judges reasonably'," and that its critical/evaluative normative ideal, the resolution of a difference of opinion through critical discussion, must be achieved "in accordance with critical norms of reasonableness" (van Eemeren and Grootendorst 2004, pp. $123,53){ }^{3}$ A fundamental task, then, of any theory of argument

\footnotetext{
${ }^{1}$ Rationality is typically understood to have at least three dimensions: (i) theoretical, cognitive or epistemic rationality (dealing with what to believe or accept); (ii) practical, instrumental or means-end rationality (dealing with what to do in order to achieve some end); and (iii) evaluative rationality (dealing with the evaluation of ends or goals) (Rescher 1988, p. 8). This paper will focus primarily on theoretical rationality, though the concerns motivating it can be seen as applying across the board.

${ }^{2}$ Some theorists prefer the language of reasonable to that of rational, sometimes making a principled or theoretical distinction between them. While recognizing the differences in connotation and variability in usage, this paper makes no distinction between these terms, treating each as having the basic, pre-theoretical connotation agreeable to reason or in accordance with reason. Ultimately, the paper is interested in the norms properly applicable to reasoning and argument-in their nature, and the kinds of principles and standards that properly underwrite them. The paper uses the language of $r a-$ tionality in discussing these norms.

${ }^{3}$ On a Pragma-Dialectical [PD] account (van Eemeren and Grootendorst 2004, p. 132), "The reasonableness of the [argumentative] procedure is derived from the possibility it creates to resolve differences of opinion (its problem validity) in combination with its acceptability to the discussants (its conventional validity)." Pragma-Dialectics assigns a descriptive connotation to the term "rational," understanding it as meaning the use of the faculty of reasoning, whereas with the term "reasonable" PD finds a normative connotation and assigns to it the meaning the sound use of the faculty of reasoning (van Eemeren and Grootendorst 2004, p. 124). In this paper, the notion of rationality is understood to have a normative connotation. Thus, the term
}

(C) David Godden. Informal Logic, Vol. 35, No. 2 (2015), pp. 135-166. 
is to supply, whether by manufacture or import, some theory of rationality. For ease of reference I will call these theories of argumentative rationality.

This paper considers the nature of argumentative rationality and the manner in which the norms of rationality can be prescriptive over arguers and audiences. While it does not aim to provide a theory of argumentative rationality, it seeks to make three contributions in this area. First, noting that theories of rationality within argumentation theory are conspicuously underdeveloped, the paper locates a common, basic picture of the nature of argumentative rationality in the literature and identifies a collection of assumptions implicit in this picture. Second, having done this, the paper diagnoses a particular challenge to the argumentative picture of rationality coming from the psychology of reasoning. Roughly, the challenge is that of bounded rationality, which includes a requirement that normative theories of rationality-including rational norms themselves-accord with descriptive accounts of our cognitive, psychological competencies. This requirement presents several challenges for normative theories of rationality and particularly for the argumentative picture of rationality. One problem is that bounded rationality seems to psychologize our rational standards lowering the normative bar to one that is merely descriptive of our optimal, if untutored, reasoning behavior. (This problem is not the focus of the present paper, but see (Godden 2012).) A second problem, which is the focus of this paper, is that prevailing descriptive theories of the structure and operation of human rationalityspecifically the dual-process theory-do not align well with the picture of rationality presumed within argumentation theory, thereby making the normative theories descriptively, or psychologically, inadequate. Like the first problem, bounded rationality again seems to require a revision of our normative picture of argumentative rationality making it descriptively adequate, if it is to retain its prescriptive force. As a remedy to this problem, the third contribution of this paper is to suggest a different conception of the nature of reasoning on which it is a social activity rather than a cognitive process, thereby recontextualizing the relationship between normative theories of reasoning understood as a justificatory activity and descriptive theories of the psychological states and processes underlying that activity. What follows is a brief sketch of the paper in terms of the three central contributions it aims to make.

"rational," as used in this paper, is intended to include the PD sense of "reasonable."

(C) David Godden. Informal Logic, Vol. 35, No. 2 (2015), pp. 135-166. 
Although the various methodological approaches to the analysis and evaluation of argumentation found in the theoretical marketplace offer competing accounts of the content and foundations of rational norms, I contend that they share a common, basic view of the nature of rationality. I begin (in section 2) by describing what I take to be that basic idea of the nature of argumentative rationality. I proceed (in section 3 ) to identify a collection of assumptions I find to be implicit in this basic picture. In addition to the assumption of normativity, I identify deontological, structuralist, and internalist assumptions, together with an assumption of reflective stability. In effect these assumptions characterize the kind of thing argumentation theorists take rationality to be.

The second part of the paper (beginning in section 4) compares this account of argumentative rationality to dualprocess theories of reasoning and rationality currently prevalent in the psychology of reasoning. This comparison is motivated by theoretical concerns about the foundations of the prescriptive force of rationality as a norm. Bounded rationality advises that the prescriptivity of rational norms is determined in part by their psychological adequacy - i.e., the extent to which they accurately represent the reasoning potential of agents whose cognitive resources are both finite and fallible. Such an attitude implies that there should be a high degree of correspondence between normative (e.g., argumentative) and descriptive (i.e., psychological) theories of rationality if the former hope to have prescriptive force. Yet (in section 5), I argue, such a correspondence is, for the most part, not to be found. For example, I consider O'Keefe's (1996) dual-process model of persuasion noting that existing accounts of argumentative rationality do not resemble O'Keefe's model.

If correct, argumentation theorists are faced with a crucial choice. One option is to revise our views on the kind of thing we take rationality to be, and to replace our existing theories of argumentative rationality with some dual-process account. As an alternative to this, (in section 6) I argue for an activity-based account of the nature of reasoning which retains the assumptions of argumentative rationality while recontextualizing the relationship between reasoning as a justificatory activity and the psychological states and processes underlying that activity. This allows argumentation theorists to avoid the direct challenge of bounded rationality. One can accept the descriptive findings of psychology without immediately demanding that the standards of our normative, rule-governed activities be changed accordingly.

(C) David Godden. Informal Logic, Vol. 35, No. 2 (2015), pp. 135-166. 


\section{Argumentative rationality: The basic idea}

Given the centrality of the idea of rationality to the theory of argument, it is surprising that the theories of rationality offered within argumentation theory are, for the most part, conspicuously underdeveloped. ${ }^{4}$ While each perspective (rhetorical, dialectical, and logical/epistemic) typically lays claim to the language of "rationality" and "reasonableness," few develop a theoretically robust or operationalized account of it. Given the inherent normativity of rationality, this might not be surprising. The word "rational" is an honorific, a term of compliment, and to say that something (an argument, position, or person) is rational is "a way of expressing approval" (Willard 1989, p. 156). Thus, theorists tend to use the language of rationality as a guise or a gloss for their preferred set of norms without specifying precisely what those norms are. As such, I take the identification and articulation of the notion of argumentative rationality together with the underlying assumptions implicit in it to be a central theoretical contribution of the paper, and one that has not been previously undertaken in the argumentation theoretic literature.

Perhaps we should not expect to find a single account of argumentative rationality common to all theories in the marketplace. Different methodological perspectives typically differ on points concerning the content and foundations of rational norms. That is, competing theories tend to disagree about what should count as a good reason, and how the goodness of reasons should be determined and explained. Yet, despite these differences, theories of argument tend to share a common picture of the nature of rationality - of what it is to be rational. Basically, to be rational is to base one's views on reasons by rightly responding to them. Argumentative persuasion occurs by means of reasons. To be persuaded by a reason is to base one's acceptance of a claim on the reasons provided such that there is a causal and explanatory relationship between one's acceptance of a claim and the strength of the reasons for it. The core idea of rationality, then, is that "rational beliefs must be based on reasons" (Brown 1988, p. 38). Or, as Siegel (1988, p. 32) puts it: "To be a rational person is to believe and act on the basis of reasons" (cf. Siegel 2004, p. 598).

\footnotetext{
${ }^{4}$ In what follows I will draw upon what is perhaps the most robust theory of argumentative rationality available, proposed by Siegel $(1988,1997,2004)$ and developed in a series of papers by Biro and Siegel (Biro and Siegel 1992, 2006; Siegel and Biro 1997, 2008). While theirs is an avowedly epistemic theory, I claim that the picture of the nature of argumentative rationality, as opposed to its content or foundations, they describe is not uniquely epistemic, but is commonly shared by theories of argument regardless of methodological approach.

(C) David Godden. Informal Logic, Vol. 35, No. 2 (2015), pp. 135-166.
} 
Further, to properly base one's acceptance of claims on reasons, one must respond rightly to them. "To be a critical thinker," Siegel (1988, p. 32) continues, "is to be appropriately moved by reasons" - a condition which he $(1997$, p. 2$)$ explains as follows: "to say that one is appropriately moved by reasons is to say that one believes, judges, and acts in accordance with the probative force with which one's reasons support one's beliefs, judgments and actions." Being appropriately moved by reasons, then, relies on a standard of evidence proportionalism, perhaps first articulated by empiricists like Locke (1690, IV.xix.1; 1975, p. 697) and Hume (1777, X.i.87; 1975, p. 110), which Engel (2000, p. 3) defines as follows: "In general a belief is rational if it is proportioned to the degree of evidence that one has for its truth." Pinto (2006, p. 287) similarly explains rationality along the lines of a qualitative evidence proportionalism whereby "rationality is a matter of making our attitudes towards propositions or propositional contents appropriate to the evidence which shapes them."

\section{Argumentative rationality: Assumptions}

This admittedly rudimentary picture of the nature of argumentative rationality is enough to begin the analytical task of articulating some of the assumptions embedded within it. On my analysis, these assumptions comprise at least five rough kinds: (i) the normativity assumption, (ii) deontological assumptions, (iii) structuralist assumptions, (iv) internalist assumptions, and finally (v) the assumption of reflective stability.

\subsection{Normativity assumption}

Our use of "rational" as an honorific reveals the first assumption. "Rationality," like "knowledge," is not merely descriptive but is, instead, a success term. ${ }^{5}$ While the criteria for attributing rationality are behavioral, attributions of rationality seek to confer some particular normative status upon their recipients. (Just as, to use Williams's (2001, p. 11) example, the criterion crossing the finish line before any other competitor, is a behavioral criterion used to confer the normative status of winning the race upon the victor.) The language of "rationality" can thus never be naturalized or reductively defined. Rather, judgements and at-

\footnotetext{
${ }^{5}$ The discussion offered here closely parallels Williams's (2001, p. 11) discussion that knowledge is inherently normative.
}

(C) David Godden. Informal Logic, Vol. 35, No. 2 (2015), pp. 135-166. 
tributions of rationality are value judgements of a certain kind. Instead of merely identifying descriptive conditions - properties that we either do or do not possess - the criteria for value judgements and attributions prescribe normative standardsconditions we ought to satisfy, regardless of whether we actually do. Call this the normativity assumption.

\subsection{Deontological assumptions \\ (accountability, obligation, entitlement, and voluntarism)}

Our usage of "rational" as honorific indicates not only the inherent normativity of rationality, but also that we hold the attitudes at stake in argumentation to be rightly subject to what Strawson (1962; cf. Jäger 2004: 1) called reactive attitudes. ${ }^{6}$ We take ourselves rightly to praise and blame people not only for what they do but for what they believe, and as such we hold them responsible for their beliefs as well as their actions (Godden 2010). Call this the accountability assumption.

The accountability assumption begins to reveal the deontological aspects of argumentative rationality, according to which rational agents have obligations pertaining to their cognitive comportment as well as their communicative activities (Aijaz, McKeown-Green and Webster 2013). That is to say, rational agents have rational obligations. Consider two examples of such rational duties. One is to provide reasons, if called upon to do so, justifying one's view or demonstrating one's entitlement to it. A second is to surrender one's view-i.e., to exchange it for, or modify it in accordance with, some alternative viewwhen presented with better reasons for that alternative, competing view. ${ }^{7}$ Whether for its own sake or as a means to some advertised end (e.g., truth or reconciliation) we are prepared to undertake these rational responsibilities as norms for our cognitive and discursive behavior, and to hold ourselves and each other

\footnotetext{
${ }^{6}$ This paper seeks to work with a neutral account of the nature of those attitudes at stake in argumentation. Some theories explicitly consider these attitudes as cognitive (e.g., beliefs), while others seek to externalize such cognitive attitudes treating them as communicative (e.g., commitments). When discussing or quoting from these different theories, I will employ their chosen terminology. While, on occasion, I explicitly make claims about the cognitive attitudes involved in argumentation, for the most part I seek to use the language of "views," "claims," and "reasons" which I intend to be neutral between cognitive and communicative accounts of them.

${ }^{7}$ In previous work (Godden 2014), I have sought to explain this pair of obligations as arising from the obligation to say why one is right (i.e., correct) in refusing to exchange or modify their present view with any competing alternative (e.g., some other view on the table in the argumentative exchange).
}

(C) David Godden. Informal Logic, Vol. 35, No. 2 (2015), pp. 135-166. 
accountable to these norms insofar as we are able. Call this the obligation assumption.

The counterparts to rational obligations are rational entitlements. Satisfying our rational responsibilities grants us certain rational entitlements. For example, by providing adequate reasons for our view, we establish and demonstrate our rational entitlement to that view. Thus, Pinto $(2006,2009)$ explains the normative force of reasons as entitlement establishing, while deontological theories of justification explain the concept of epistemic justification in terms of satisfying, or at least not violating, any relevant duty, obligation, rule or regulation (Alston 1989 , p. 85). Entitlements are the permissive, rather than the obligatory, side of rational normativity. Having demonstrated our entitlement to a view, we have established that we are permitted to hold (possess) it, and to use it in certain kinds of ways (e.g., as premises for future inferences). We have further established our rational right to assert it, rather than to retract or revise it. Call this the entitlement assumption.

A final deontological assumption is, in some sense, a consequence of the first two, together with the principle that ought implies can. If we ought to align our views with our reasons, then the assumption is that we can do so. The basic idea of this assumption is expressed in a variety of ways: that we can act and accept claims on the basis of reasons (Johnson); that we can be appropriately moved by reasons (Siegel); that we can make our cognitive attitudes fit our evidence (Pinto). The assumption here is that we have the ability to align our views with our reasons. Call this the voluntaristic assumption.

\subsection{Structuralist assumptions}

(basing, causal, rule, and tracking)

Together these deontological assumptions rely upon the further assumption that our views can be based on reasons at all. For a view to be held rationally, it must be held because of the reasons we have for it. Minimally, the idea here is that our possession (adoption or retention) of some rationally held view is explained in terms of the reasons we have for it. Indeed, our merely possessing adequate reasons for a view can still fail to rationally entitle us to that view should we fail to actually make the connection, or draw the inference, between those reasons and the view. Call this the basing assumption.

(C) David Godden. Informal Logic, Vol. 35, No. 2 (2015), pp. 135-166. 
Frequently, this explanatory relationship is unpacked in causal terms. ${ }^{8}$ Reasons are supposed to have cognitive force upon us; they are somehow causally efficacious over our cognitive attitudes. And, to the extent that arguments occasion or involve inferences, this causal picture is only reinforced if, as Harman (1986, p. 207) claims, "[w]e normally think of inference as a causal process, in which the premises are all causally operative in producing a new belief (or other doxastic change)." Indeed it is not merely that the weight of reasons has some cognitive sway for us; rather the picture of argumentative rationality being considered makes the further assumption that in cases of rational belief the force of reasons will outweigh any non-rational, psychological forces (e.g., desires or pathologies) acting on our cognitive attitudes. Call this the causal assumption.

When taken together with the normativity assumption, the basing assumption has the further consequence that basing relationships are not merely causal or explanatory, but justificatory or entitlement-conferring also. It is not merely an agent's $a c$ ceptance of a claim that is to be explained by her reasons for it. Rather the acceptability of the claim, and thereby the agent's entitlement to hold the claim, should also be so explained. Basing relations (or connections between reasons and claims), then, are expressed in terms of rules which might be called basing rules. Basing rules, unlike the rules that comprise our rational obligations discussed earlier, are permissive: authorizing, licensing or justifying the holding of some claim because some other (set of) claim(s) is already held. Whether these basing rules are logical, epistemic, pragmatic, procedural or social, each perspective on argument either presupposes or explicitly provides some set of rules governing the operation of reasons. Brown (1988, p. 17), describing something he calls the "Classical Model of Rationality," claims that the notion of rules is essential to rationality, saying "the rationality of any conclusion is determined by whether it conforms to the appropriate rules." Quite often basing rules are conceived of as warrants, or inference licenses,

\footnotetext{
${ }^{8}$ To test your intuitions here, consider a proponent who, when challenged, provides a set of reasons for her standpoint and each of those reasons is shown, to her own satisfaction, to be defeated. For such a proponent, we might conclude that her espoused reasons were not her real reasons, precisely because her espoused reasons are not properly causally connected to her standpoint and thereby not in accord with the basing assumption. As this process continues and her position remains steadfast, we increasingly come to conclude that her standpoint is not connected with any reasons whatsoever, and as such that she does not hold the standpoint rationally.

${ }^{9}$ Siegel (2004) agrees with this view, but points out that rules need only be involved in reasoning ex post facto at an evaluative stage rather than at the stage of execution.
}

(C) David Godden. Informal Logic, Vol. 35, No. 2 (2015), pp. 135-166. 


\section{David Godden}

yielding the idea that reasoning (or inference) is not merely any succession of mental states, but is instead a rule-governed activity of the mind like calculation or playing chess. Call this the rule assumption.

Finally and as noted earlier, to base one's acceptance of a claim on a reason, one must, at some level, be cognizant of the (purported) connection between the reason and the claim. For example, a rational agent should be able to cite her reasons, and perhaps even the rules that (purportedly) make her reasons good ones, if called upon to do so. If being rational involves recognizing the probative merits and consequences of reasons, and acting accordingly, then rational agents should monitor and keep account of the acceptability of reasons and the claims based on them. ${ }^{10}$ As such, one of our obligations as a rational agent seems to be that we should track our reasons for our views. At least, we should track the basing relations between the claims at issue and the reasons on offer in our argumentative exchanges. Indeed, it is not merely the basing relations among the claims used in an argument that require tracking. Since, for example, a paradigm of irrationality is holding manifestly inconsistent beliefs, other logical, epistemic, and dialectical relationships such as commitment, consistency, coherence, relevance, and consequence must also be tracked. ${ }^{11}$ At least, we are obliged to maintain consistency among the sub-set of our beliefs that is on the table in an argument. Minimally, the picture of argumentative rationality sketched above presupposes that, at least for the duration of an argumentative exchange, we track the basing relations together with a variety of other relations pertaining to the claims that are on the table in an argument. Call this the tracking assumption.

\subsection{Internalist assumptions (accessibility and articulability)}

Implicit within many of these structuralist and deontological assumptions, one can also detect a pair of internalist assumptions.

\footnotetext{
${ }^{10}$ This assumption can have a broad interpretation, whereby we always actively track the basing relations among all of our beliefs both occurrent and tacit, which is both psychologically and argumentatively untenable. Minimally, what is presupposed is that we track the reasons on the table in some argumentative transaction.

${ }^{11}$ Again, this assumption has a broad interpretation on which it is almost surely false. For example, fallible agents arguably ought to believe that they have some false beliefs thereby guaranteeing that their entire belief set is inconsistent. But this is not the scope of consistency tracking envisaged here.
}

(C) David Godden. Informal Logic, Vol. 35, No. 2 (2015), pp. 135-166. 
When we base our views on reasons in such a way that we can be held accountable for the views that we hold, we must do so consciously and with some awareness of those reasons. ${ }^{12}$ Pinto (2001, p. 10) articulates this assumption when he describes argument as "the attempt to modify conscious attitudes through rational means." Part of what it is to adopt or hold a view rationally, on the basis of reasons, then is to be able to identify those reasons on the basis of which we hold the positions that we do. Call this the accessibility assumption.

Lastly, the idea that we are normally conscious of our reasons informs a more commonly explicit tenet of argumentation theory: that rational arguers are capable, normally and upon reflection, of articulating their reasons for their views. Indeed theories typically make it an obligation that rational arguers be able to do so if called upon or challenged by an interlocutor. Call this the articulable assumption.

\subsection{Assumption of reflective stability}

A final assumption about the nature of argumentative rationality concerns not how a view is rationally adopted, but instead concerns how it is held-how rational beliefs behave once they are adopted. The idea here is that our views, once settled upon, stay that way - they do not randomly change. This is not meant to presuppose a thick foundationalism where the reasons on which a belief is adopted actively persist as the basis on which the belief continues to be held. Rather it merely claims that, once settled, rationally held conscious mental attitudes do not change without reason-that they are reflectively stable. Call this the reflective stability assumption.

\section{Rationality and psychology of reasoning}

\subsection{Perspectives on evaluation of theories of argumentative ra- tionality}

Having identified a collection of assumptions about the nature of rationality I argue are implicit in argumentative conceptions

\footnotetext{
${ }^{12}$ To test your intuitions about this assumption, suppose that you are presented with a knock-down argument for $p$ while asleep or under hypnosis. As it turns out, you process the information of the argument in your sleep-you are somehow appropriately moved by the reasons in the argument-and you wake up appropriately believing that $p$. Yet, you were completely unconscious of this entire process occurring. Would such a belief change have been rational for you?

(C) David Godden. Informal Logic, Vol. 35, No. 2 (2015), pp. 135-166.
} 
of it, I proceed to consider what bearing psychology has on rationality.

There are a variety of ways in which theories of argumentative rationality can be evaluated. First, they might be evaluated according to their theoretical adequacy. For example, Biro and Siegel $(1992,2006,2008)$ have argued that the PragmaDialectical account is not theoretically adequate because its proposed system of norms can yield argumentatively undesirable (whether non-optimal or plainly unacceptable) results. Similarly, it might be argued that a proper account of rationality takes a procedural or dynamic, rather than a structural or static, form. To date, rationality debates in the argumentation literature have focussed primarily on issues of these types.

Another way in which theories of rationality can be evaluated is on the basis of what I will call their descriptive or psychological adequacy. That is to say, to what degree do our normative theories of rationality accord with the findings of psychologists concerning the nature of human rationality and our overall rational competency? For example, Hume wrote in his Treatise that "Reason is, and ought only to be, the slave of the passions, and can never pretend to any other office than to serve and obey them" (1739, II.iii.3; 1989, p. 415). Supposing that to be true, any theory of argumentative rationality that accorded reason some other relation to the passions would be psychologically inadequate.

How, then, is human rationality conceived as it is studied by psychologists?

\subsection{Psychology and rationality: the standard picture}

Historically, psychological theories of rationality and reasoning began by holding the formal theories of logic and decision theory developed by philosophers and mathematicians as ideal standards of rationality against which human behaviour was to be measured. ${ }^{13}$ This "Standard Picture" is described by Stein (1996, p. 4) as follows:

According to this picture, to be rational is to reason in accordance with principles of reasoning that are based on rules of logic, probability theory and so forth. If the standard picture of reasoning is right, principles of reasoning that are based on such rules are normative princi-

\footnotetext{
${ }^{13}$ For an overview of the history and controversies surrounding the development of psychological theories of rationality see Rysiew (2008) and Stanovich (1999, ch. 1), upon which the sketch offered in this paper draws.

(C) David Godden. Informal Logic, Vol. 35, No. 2 (2015), pp. 135-166.
} 
ples of reasoning, namely they are principles we ought to reason in accordance with.

Yet, widely known experiments such as Wason's (1968) selection task (for deductive reasoning) and Tversky and Kahneman's (1982) representative description task (for probabilistic reasoning) convincingly indicate that human reasoners predictably and systematically fail to reason in accordance with these idealized norms. ${ }^{14}$ When viewed in the context of our general and remarkable success in navigating the world, our apparent failures in these seemingly rudimentary reasoning tasks is perplexing and paradoxical (Evans and Over 1996). In addition to giving rise to a variety of different accounts of the underlying nature of human reasoning (including the mental logic theory, the mental models theory, and the heuristics and biases program) these experimental findings also served as the catalyst for a series of debates about how their results should be interpreted (Rysiew 2008). What do they really tell us about the nature of human rationality, and about the rational norms to which we should be held accountable? ${ }^{15}$

\subsection{Bounded rationality}

One response questions the fitness of the standards of logic and the probability calculus for cognitively finite and fallible human reasoners. This response turns on the idea that we are boundedly rational beings (Simon 1957) with limited and sometimes faulty cognitive resources (e.g., memory and computational faculties) the effectiveness of which is further impinged upon by practical and situational constraints (e.g., time and distraction). Indeed some (Gigerenzer 2000, 2008; Gigerenzer and Selten 2001) argue that we are best characterized as a species of satisficers rather than optimizers - cognitive success is a matter of getting by rather than of perfection or even excellence.

If correct, it seems wrong to hold ourselves to a set of rational standards that we are constitutively incapable of attaining. As Stich (1990, p. 27) put it, "it seems simply perverse to judge that subjects are doing a bad job of reasoning because they are not using a strategy that requires a brain the size of a blimp." Theories of bounded rationality (as opposed to ideal rationality)

\footnotetext{
${ }^{14}$ For a discussion of the various theoretical responses the experimental findings of Wason's selection task, and their possible implications for human rationality see Manktelow and Over (1987).

${ }^{15}$ This paper will not review this debate, surveys of which can be found in Stein (1996) and Stanovich (1999).
}

(C) David Godden. Informal Logic, Vol. 35, No. 2 (2015), pp. 135-166. 
take facts about the constitutive limitations of human reasoners as relevant in determining rational norms.

In view of considerations like these, Baron $(1985, \mathrm{p} .11)$ distinguished between normative and prescriptive models, where prescriptive models take the ought implies can axiom seriously. "A good prescriptive model takes into account the very [cognitive and situational] constraints on time [and resources], etc., that a normative model is free to ignore [in providing an idealized norm]." With this distinction, it is possible to ask whether a normative system should have prescriptive force over an agent (in some situation).

Finally, the idea that there are constitutive limitations on human reason provides the basis for the idea of human rational competency (Stein 1996), understood as our rational potential: the limits of our rational abilities given our cognitive constraints. Our performance on some particular occasion can fall short of our potential and this might be seen as an error in reasoning. But errors of reasoning are just that-mistakes; they are not evidence of irrationality, which is instead understood as a systematic defect in our competency.

\subsection{Panglossians, meliorists, and apologists}

These ideas precipitated three attitudes towards the rational abilities of humans (Stanovich 1999, pp. 5 ff.): the Panglossian, the Meliorist, and the Apologist. The Panglossian holds that human irrationality is a priori impossible. There is no gap between the descriptive, prescriptive, and normative theories of reasoning. The only rational norms fit for us are that we should reason to the best of our potential (competence), and the best evidence of our potential is what we actually do (our performance). Thus, experimental results of apparent bias are not evidence of human irrationality, but are instead "normalized," since our performance in the task is evidence of our rational competence, which in turn comprises the norms of human rationality (see Stein 1996, pp. 231 ff.). For the Panglossian, human beings are the best reasoners they can be and that is all there is to the very idea of good reason. A Meliorist, by contrast, is much more inclined to interpret experimental results as evidence of human irrationality. For the Meliorist, our cognitive performance frequently falls short of our rational competency, which our rational norms are not based upon but do, in fact, represent more-or-less accurately. Thus, most of the rational norms we discover actually have prescriptive force for us, but, as evidenced by reasoning experiments, we frequently fail to reason in accordance with those prescriptive norms. Finally, the Apologist shares with the

(C) David Godden. Informal Logic, Vol. 35, No. 2 (2015), pp. 135-166. 
Panglossian the idea that experimental results do not tend to demonstrate human irrationality, and further that our untutored rational performance is presumptive evidence for our rational competence which, in turn, forms the basis for the prescriptive force of rational norms. Yet, the Apologist admits that there is a considerable gap between ideal rational norms, which are externally determined, and rational norms that have prescriptive force for boundedly rational agents. The Apologist holds that we normally reason to the best of our ability, which is as much as can be expected from us, but in contrast to the Panglossian, this may not always be to reason very well in the grand scheme of things. Many norms simply fail to have prescriptive force for us. Thus, experimental results of reasoning biases are not signs of irrationality but are evidence that human rational competency is such that the normative bar must be lowered in order to provide a fit prescriptive standard for us.

\subsection{Dual-process theories of rationality and cognition}

Evolutionary approaches to psychology commonly yield the view that the human mind is a kluge (Marcus 2008): the mindand so the rational mind - is a product of evolution and as such is composed of an ad-hoc collection of evolutionarily (i.e., locally) satisfactory systems, rather than a single computational machine designed to the standards of some universal rational ideal. In this vein, recent theories of rationality have adopted a dualprocess view, postulating two kinds of processes which together jointly effect belief formation and revision (Wason and Evans 1975; Evans and Frankish 2009). ${ }^{16,17}$ (Often, these processes are presented as fully modular, structurally and functionally independent systems.) While there is a great variety of such accounts (surveyed in Stanovich 1999, Ch. 5; Osman 2004; Evans 2008; Evans and Frankish 2009), they share the basic idea that reasoning and cognition are accomplished by a confluence of two separate kinds of processes. Processes of the first kind (system-1)

\footnotetext{
${ }^{16}$ For histories of dual-process accounts of cognition see Evans (2004) and Frankish and Evans (2009).

${ }^{17}$ In addition to dual-process accounts, there is the hypothesis that human rationality is best understood using a Bayesian model of probability (Oaksford and Chater 2007, 2009; Oaksford, Chater and Hahn 2008). This view informs the position (Corner and Hahn 2013) that a Bayesian model of rationality provides the proper account of argumentative rationality. Although Bayesian approaches to argumentation are increasingly prominent (Korb 2003; Hahn and Oaksford 2007; Zenker 2013), consideration of the Bayesian approach and engagement with the position that Bayesian accounts of rationality work for argumentation theory is beyond the scope of the present paper.
}

(C) David Godden. Informal Logic, Vol. 35, No. 2 (2015), pp. 135-166. 
are unconscious, associative, domain-limited, automatic and connectionist (i.e., happen in parallel), while processes of the second kind (system-2) are conscious, rule-based, domaingeneral, deliberate and computational (i.e., happen in sequence). Table 1 (see next page) (Evans 2008, p. 257) provides an overview of many of the properties typically attributed to each system (cf. Stanovich 1999, p. 145; Frankish and Evans 2009, p. $15)$.

The empirical case for two-systems theories rests on what Sloman (1996, p. 11) has called a bistability criterion whereby agents are cognitively impelled towards two incompatible responses to a situation or problem. A perceptual analogue for this cognitive state would be looking at a Müller-Lyer illusion: one cognitively knows that the lines are of equal length though the one still appears to be longer. Knowing cognitively doesn't offset how it looks perceptually, and vice versa. That the two different, contradictory results are not somehow reconciled or offset is taken to be evidence that they are the independent outputs of two separate systems.

Such results are reported by subjects in a wide variety of experimental reasoning tasks thought to involve cognitive biases. The dual-process explanation of this bistability posits the existence of two independent cognitive systems which, when they produce conflicting outputs in some task, impel the subject's cognitive attitudes in different and inconsistent directions. While dual-process theories can be viewed as neutral on a variety of issues in the psychology of reasoning (e.g., whether system-2 processes are accomplished on the theory of mental models or mental rules (Evans 2003, p. 457)) part of the empirical force of dual-process theories is their success in explaining the results of the heuristics and biases experiments (Frankish and Evans 2009, p. 13). The hypothesis is that a bias occurs when a system-1 process, which is usually a reliable or effective heuristic in spcific domains of application, operates outside of its domain of reliability or effectiveness. When a system-2 process also produces a result on the same problem, these results can conflict. In this way, even when people are told the normative, system-2 rule to apply, they can fail to do so when a system-1 process overrides their efforts at conscious deliberation, calculation or inference, and the attendant application of the relevant rule(s). System-1 processes should not be seen as necessarily biased or as sources of rational error. Instead, system-1 processes can be understood as representing a collection of "fast and frugal" heuristics that have evolved in the human mind allowing us to survive in the sorts of environments in which we live, while making efficient use of our limited and scarce cognitive resources.

(C) David Godden. Informal Logic, Vol. 35, No. 2 (2015), pp. 135-166. 


\begin{tabular}{|l|l|}
\hline System 1 \\
\hline Cluster 1 (Consciousness) \\
\hline Unconscious (preconscious) & Conscious \\
Implicit & Explicit \\
Automatic & Controlled \\
Low effort & High effort \\
Rapid & Slow \\
High capacity & Low capacity \\
Default process & Inhibitory \\
Holistic, perceptual & Analytic, reflective \\
\hline Cluster 2 (Evolution) & Evolutionarily recent \\
\hline Evolutionarily old & Individual rationality \\
Evolutionary rationality & Uniquely human \\
Shared with animals & Linked to language \\
Nonverbal & Fluid intelligence \\
Modular cognition & Rule-based \\
\hline Cluster 3 (Functional characteristics) \\
\hline Associative & Domain general \\
Domain specific & Abstract \\
Contextualized & Logical \\
Pragmatic & Sequential \\
Parallel & Egalitarian \\
Stereotypical & Heritable \\
\hline Cluster 4 (Individual differences) \\
\hline Universal & Linked to general intelligence \\
Independent of general intelli- \\
gence & \\
Independent of working & Limited by working memory \\
memory & capacity \\
\hline
\end{tabular}

Table 1: A comparison of system-1 and system-2 properties. Reproduced from (Evans 2008, p. 257).

Standardly, processes identified as belonging to system-1 are characterized as effective and advantageous cognitive strategies - fast and frugal heuristics, or informational shortcuts that provide quick, good-enough answers to simplified problems while making efficient use of limited cognitive resources. As such, though it is granted that heuristics can become biases when applied in problem spaces outside of their evolved domain of effectiveness (reliability or prudence), the outputs of system1 processes have come to be presented as generally and presumptively acceptable, and the processes themselves as generally and presumptively rational.

(C) David Godden. Informal Logic, Vol. 35, No. 2 (2015), pp. 135-166. 
Even more pronouncedly, in response to the paradox of the abundance of practical, worldly successes of ordinary reasoners in combination with their apparent systematic normative failures in basic reasoning tasks, Evans and Over (1996) postulated two senses of rationality. Rationalityl was defined against an instrumental standard of practical success and has come to be identified with system-1 processes. Rationality2, by contrast, was defined in terms of following the normative rules of some theory of idealized rationality (e.g., logic), and has come to be identified with system-2 processes.

\section{Rationality, argumentative and psychological: A compar- ison}

How does this dual-process model of human rationality accord with the account of argumentative rationality analysed above?

In bringing together the two bodies of theory, it is comforting to recognize some points of commonality. First among these would be the mutual rejection of the logicist thesis (Henle 1962), described by Evans (2002, p. 979) as "the doctrine that logic provides the basis for rational human thought." The rejection of formal logic and the probability calculus as capable of supplying a comprehensive set of standards for rational, argumentative norms is widely agreed upon by each of the methodological perspectives (product, procedure, and process) in argumentation studies. Both disciplinary traditions seem to recognise that much of human thought and cognition, including that used in argument, is defeasible and plausibilistic rather than monotonic or quantitatively probabilistic. While our reasoning may well be rule-governed, it is not generally algorithmic in any formalistic way.

A second point of correspondence is the idea that rational norms, properly conceived, must have prescriptive force over human reasoners. Thus, there is no point in setting our rational standards impossibly high. To conclude by such means that we are irrational is to fail to explain our many cognitive successes, both in argumentation and in life. Thus, both disciplines accept the general program of bounded rationality, and with it a form of psychologism that minimally claims something along these lines:

Requirements of rationality, then, should be shaped to fit practical feasibilities, and questions of feasibility are just the sorts of questions which cognitive science often addresses. Thus, cognitive science may be relevant in set-

(C) David Godden. Informal Logic, Vol. 35, No. 2 (2015), pp. 135-166. 
ting standards of rationality, not just in assessing human prospects for meeting independently given standards. (Goldman 1993, p. 22; as quoted in Stanovich 1999, pp.

38-39.)

Despite these similarities, there is an important and striking difference in the way that each discipline conceives of the nature of rationality. Judging from the list of assumptions about argumentative rationality identified in section 3 , it would appear that argumentation theorists conceive of reasoning and rationality exclusively as a system-2 operation. Consider: while the structuralist assumptions that reasoning is a rule-governed activity involving the tracking of basing relations aligns well with the functional cluster of system-2 characteristics (like being rulebased, logical, and sequential), the structuralist assumptions do not accord at all with the functional characteristics of system-1 (such as being associative, pragmatic, and parallel). Similarly, the internalist assumptions that reasons and basing relations are consciously accessible and articulable correspond only to the consciousness and evolutionary clusters of system-2 characteristics (e.g., being conscious, explicit, and linked to language), while contradicting the same clusters of system-1 characteristics (e.g., being unconscious, implicit, and nonverbal). Finally, the deontological assumptions, that reasoning and rational change in view is a controlled or voluntary activity in which we have certain obligations and for which we can be held accountable, all correspond exclusively to system-2 characteristics (such as being controlled, high-effort, slow, and uniquely human) while being inconsistent with system-1 characteristics (of being automatic, low effort, rapid, and shared with animals). While it is beyond the scope of this paper to completely unpack each discipline's conceptual framework (and thereby identify each point of congruence and difference), I do not assert that there is a complete identity (or even a superlative similarity) between argumentative rationality and system-2 reasoning. Rather, my claim is that theories of argumentative rationality assume that rationality is system-2-like, and decidedly not system-1-like. ${ }^{18}$

\footnotetext{
${ }^{18}$ This is not to say that argumentation theorists have ignored heuristic, system-1 patterns of reasoning. For example, Walton (1996) considers defeasible reasoning to be contextualized (presumption-generating in some situations, fallacious in others) and schematic, rather than associative in nature, where premises and inferential linkages can be articulated and subjected to the rational scrutiny of critical questions.

Recently, Walton (2010) adopted the language of heuristics to describe something he calls paraschemes. Paraschemes are simplified versions of defeasible argumentation schemes, but which do not take account of any of the qualifications, rebuttals, assumptions/exceptions, critical questions, or other complicating factors normally involved in defeasible reasoning. Walton (C) David Godden. Informal Logic, Vol. 35, No. 2 (2015), pp. 135-166.
} 


\section{David Godden}

Perhaps the overarching reason for my thesis that argumentative rationality presupposes that reasoning is system-2-like in nature is that system-1 processes allow for no possibility for the very basic notion of argumentative rationality - that of basing claims on reasons, or being appropriately moved by reasons. System-1 processes do not involve reasons whatsoever. While system-1 processes (such as matching or familiarity) tend to have easily recognized inputs and can be reliable (i.e., correlate positively to the truth of their outputs), the informational cues that provide inputs to system-1 processes do not function as reasons for their corresponding outputs in any argumentatively relevant sense. As such the relationship between the inputs of system-1 processes and their corresponding outputs is not a recognizably rational one. Rather system-1 processes comprise a set of automatic and economical problem-solving routines that have proved sufficiently successful to our evolutionary forebears that they are, in us, almost instinctual - they have become evolutionarily imprinted upon our minds. Indeed the moment we seek to employ the inputs of system-1 processes as reasons, we begin to give them system-2-like characteristics. That is, having taken

(2010, p. 171) explicitly identifies paraschematic reasoning as heuristic and system-1-like.

This [paraschematic] inference represents a simplified version of the scheme that is understandable enough as a familiar heuristic, but does not take the other [complicating] factors into account. ... The heuristic takes us by a fast and frugal leap directly to the conclusion. It is the old [i.e., system-1] cognitive system of reasoning.

Walton then uses the notion of a parascheme to explain why fallacious reasoning is more persuasive for us than it ought to be. "On this hypothesis," Walton (2010, p. 180) writes, "a fallacious argument might look better than it really is because it has the basic structure of a parascheme, and therefore looks reasonable because it is a heuristic of the kind we use all the time in everyday reasoning."

As appealing as this explanation is, it mistakenly identifies paired-down versions of defeasible, schematic system-2 arguments with system-1 heuristics. There are at least two problems with this characterization of paraschemes. First, the outputs of system-2 schematic arguments and their putative corresponding system-1 paraschemes do not pass the bi-stability criterion. Applying system-2 resources (which Walton identifies as following through on the critical questions pertaining to the scheme) to the output of a paraschematic inference displaces rather than conflicts with initial result. Second, while some biases (e.g., the confirmation bias) match well with known fallacies (e.g., affirming the consequent), the vast majority of fallacies do not correspond with empirically well-established heuristics. For example, Walton (2010) invents the expert opinion parascheme (his main example in the paper) without providing any empirical evidence supporting the idea that it is a system-1 heuristic.

(C) David Godden. Informal Logic, Vol. 35, No. 2 (2015), pp. 135-166. 
notice of them we begin to make them explicit so as to begin to evaluate them according to a set of rules or standards.

\subsection{A dual-process model of persuasion}

If psychologists are right that dual-process theories best explain the nature of reasoning and rationality, and I am right that argumentative rationality corresponds only to system-2 processes, then argumentation theorists are faced with a variety of challenging questions that go to the core of the normative theories of argument we hope to supply.

In the first place, argumentation theorists must re-examine the questions of what theories of argumentative rationality should look like, and why. To fully appreciate the force of my claim that theories of argumentative rationality are exclusively system-2-like, consider what a dual-process theory of rationality looks like.

A straightforward acceptance of the dual-process account of reasoning and rationality would suggest that perhaps the best model of argumentative rationality we have to-hand is to be found in something like O'Keefe's (1996) dual-process model of persuasion. ${ }^{19}$ O'Keefe (1996, p. 62) begins by hypothesizing an elaboration continuum, which is a rough measure of the degree to which issue-relevant thinking (i.e., cognitive resources) are devoted to a reasoning task. O'Keefe proposes broad bands on this continuum which correspond to two routes to persuasion: a central route (corresponding to system-2) and a peripheral one (corresponding to system-1). Cases of high elaboration occur through "[c]entral route persuasion, [which] comes about through extensive issue-relevant thinking: careful examination of the message's information and arguments, consideration of other issue-relevant material (e.g., arguments ...) ... [and] 'systematic' processing by the receiver" (p. 62). By contrast,

the 'peripheral route' represents the persuasion processes involved when elaboration is relatively low. Peripheral route persuasion comes about because the receiver employs some heuristic principle, some simple decision rule, to evaluate the advocated position. For example, receivers might be guided by whether they like the communicator, or by whether they find the communicator credible. Thus in such cases receivers are said to engage in heuristic (rather than systematic) processing; instead of

\footnotetext{
${ }^{19}$ O'Keefe's model is explicitly based on an amalgamation of two theories in the social psychology of persuasion: Petty and Cacioppo's elaboration likelihood model (ELM) (Petty \& Cacioppo, 1986) and Chaiken's heuristicsystemic model (HSM) (Chiaken, 1987).

(C) David Godden. Informal Logic, Vol. 35, No. 2 (2015), pp. 135-166.
} 
engaging in extensive issue-relevant thinking, they employ decision-making short-cuts. (O’Keefe 1996, p. 62.)

Which route is taken on any occasion depends on a variety of factors including motivation (e.g., personal relevance of topic and personal disposition to critical thinking and deliberation) and ability (e.g., lack of distraction and prior knowledge) (p. 63). High levels of motivation and ability are hypothesized to correlate to central route persuasion, while lowered levels of either increase the likelihood that peripheral route processing will occur (p. 63).

There is not a perfect correspondence between O'Keefe's account and dual-process theories of reasoning standardly conceived, since O'Keefe holds that the two routes are neither exhaustive nor mutually exclusive, but instead represent "conveniently idealized extremes on the underlying continuum of issuerelevant thinking" (p. 62). Nor is there a perfect mapping onto models of argumentative rationality, since O'Keefe argues that central route persuasion (or lack thereof) occurs as a result of a balance of favorable and unfavorable thoughts about the advocated position (p. 63) and not as a result of any specifically rational deliberation. For example (p. 64), elaboration direction, or a "proattitudinal" position (explained as occurring "[w]hen the advocated position is one toward which the receiver is already favorably inclined") is hypothesized as the primary determining factor in the results of central route persuasion. Thus, even central-route persuasion would be susceptible to factors such as belief-bias, though this can be counter-balanced or even overridden by "close scrutiny of the message material," including arguments (p. 64). As O'Keefe notes, his dual-process model of persuasion calls for "[a]n expanded conception of rationality" (pp. $67 \mathrm{ff}$.) on which "the use of specific heuristics can be rational" (p. 68). Nor are heuristics rightly understood on a Walton-like model of defeasible but presumptive patterns of centralroute persuasion (system-2 reasoning). Rather, O'Keefe argues that "the non-systematic reliance on [e.g.,] expertise (as embodied in the use of the credibility heuristic) is arguably rational" (p. 68).

My initial point is that existing theories of argumentative rationality typically do not look like this - not even remotely. Thus, there is a pronounced divergence between the psychologi$\mathrm{cal}$ and the argumentational accounts of the nature of rationality. This would tend to show that theories of argumentative rationality are not psychologically adequate - they do not accurately represent the nature of human rationality or human rational capacities.

(C) David Godden. Informal Logic, Vol. 35, No. 2 (2015), pp. 135-166. 


\subsection{Theoretical consequences and alternatives}

The framework of bounded rationality implies that there are important consequences to the normative standing of psychologically inadequate theories - namely that they fail to be prescriptive. What responses are available to the argumentation theorist who hopes to supply a prescriptive theory of argument appraisal?

One option is to revise theories of argumentative rationality so that they better accord with a dual-process account. This option would better enable the theory to claim that its norms have prescriptive force, but would run the risk of so changing the content of those norms that they might no longer yield "rationally"-in the old sense of the term-acceptable results. For example, one would have to admit that the result of a successful application of some system-1 heuristic, such as the availability heuristic, is presumptively rational. A further consequence of this option would be to concede that rational views are not always based on reasons in any usual sense (e.g., when they are the result of system-1 processes). Rhetorical theorists who have sought to expand the boundaries of rationality, or theorists who have sought to include unreasoned judgements (e.g., Govier 1999) in our web of rational belief, might find such a revision welcome.

But the costs of such a position are high. It is easy to pick the acceptable aspects of our cognitive or argumentative proclivities and find justification for them on a dual-process type of account. But having to concede that the putatively unacceptable or irrational aspects are thereby made rational just because they can be explained on a two-system account seems to deprive our rational standards of any normative force. Apologistic and Panglossian attitudes towards the requirement of bounded rationality involve a psychologism whereby not only does ought imply can but does implies ought-i.e., that performance delineates competence, which in turn prescribes norms.

Some seem quite comfortable with this approach. Pelletier and Elio (2005, p. 20), argue that "deductive reasoning has a 'normative standard' that is 'external' to people whereas default reasoning has no such external normative standard ... Here there is no external standard of correctness other than what people actually infer." Accordingly, reasoning performance marks not only competence norms but the very standards of rationality underlying these performances. To give a specific example, Harman (1986) has argued that we are constitutively incapable of tracking all the basing relations among our beliefs. As a consequence, not only are many structuralist inclinations of argumen-

(C) David Godden. Informal Logic, Vol. 35, No. 2 (2015), pp. 135-166. 
tation theorists misguided (indeed coherentist inclinations would be equally misguided for similar reasons), but the results of such experiments as the debriefing paradigm are not evidence of irrationality, notwithstanding our intuitions to the contrary. If Harman is right then it would seem that theories of argumentative rationality should abandon any pretense to the idea that tracking reasons and other evidential relationships should have any role in our notion of rationality. I have argued (Godden 2012) that such an Apologist attitude is mistaken, and that, as claimed in the literature on individual differences (Stanovich 1999), we should not accept that performance delineates competence-or, more to the point, that lack of performance implies incompetence - in any straightforward way.

A second alternative ${ }^{20}$ is to take the position that a theory of argumentative rationality needn't be a theory of rationality in general, and as such that its incongruence with the rationality supposedly inherent in system-1 processes is not a criticism of argumentation-specific accounts of rationality. Rather, as Evans and Over (1996) proposed, it can be granted that there is a kind of rationality, rationality1, that pertains to system-1 processes, and a different rationality, rationality2, that pertains to system-2 processes, and argumentative rationality only concerns the latter. As I see things, such a move yields manifestly unacceptable consequences. First, since the outputs of system-1 processes are judgments, they can have argumentative roles (by functioning as premises or conclusions). As such, a theory of argumentative rationality ought to have something to say about their rational acceptability. Yet, taking the proposed route makes the concession that argumentative theories of rationality do not pertain to these elements of argument. So conceived, the theory of argumentative rationality is not only an incomplete theory of rationality generally, it is not a complete theory of rational argumentation. Together with this is the equally unpalatable consequence that the theory of argumentative rationality will lose its normative, prescriptive force. That a judgment or inference is not argumentatively rational will no longer be a criticism of it, since arguers will always be able to appeal to some other standard of rationality that they can claim to have met, but which is, by hypothesis, entirely outside the scope of argumentation theory. At this point, the aims of the rational appraisal of argument, as it is traditionally conceived in argumentation theory, have been entirely lost.

A third alternative is to reject the idea that the findings of psychology are relevant to the normative dimensions of argu-

\footnotetext{
${ }^{20}$ Suggested by one reviewer.

(C) David Godden. Informal Logic, Vol. 35, No. 2 (2015), pp. 135-166.
} 
mentative rationality, and with it the naturalized attitude of bounded rationality. By ignoring our rational abilities, though, we surrender the claim that ought implies can, and thereby risk sacrificing any prescriptive force our theoretical norms might aspire to. So, conceding that the findings of psychology have some relevance to the foundation and specification of rational norms, what is an adequate balance between psychologism and logicism? How can argumentative norms retain prescriptive force as rational norms, when they seem to presuppose a picture of the nature of rationality that does not accord well with empirical, psychological accounts?

\section{Reasoning: Social activity versus psychological process}

The proposal offered here does not seek to force a choice between psychologism and logicism; nor does it advocate charting a middle course between them. Instead, it invites argumentation theorists to adopt a different view of the relationship between the activity of argumentation - and reasoning itself - and the psychology of belief.

The traditional picture, due to thinkers like Harman (1970) and Alston (1989), holds that the basing relationship between a belief and its reasons is a causal one occurring at the level of the psychological states of the believer. This picture produces a spectatorial conception (Leite 2004, p. 222) of the activity of justification:

The justificatory status of a person's belief is determined by certain facts which obtain prior to and independently of the activity of justifying. The activity itself plays no role in determining the justificatory status; it is simply a secondary and optional matter of attempting to determine and report, as far as is conversationally necessary, the prior and independent facts which determine the justificatory status of one's belief. Consequently, even if things go badly wrong in the course of the activity, that will not determine one's actual justificatory status.

Leite argues that this is a mistaken conception of the nature of justification and its relationship to the activity of justifying. The activity of giving reasons, according to Leite (pp. 226-227), does not report on pre-existing facts about one's own psychological states, and it does not require or involve any special, introspective self-knowledge.

By contrast, according to Leite (pp. $238 \mathrm{ff}$.), reasoning is a normative, rule-governed activity (cf. Campolo 2005; Melser 2004; Laden 2012; Turner and Wright 2005) rather than a psy-

(C) David Godden. Informal Logic, Vol. 35, No. 2 (2015), pp. 135-166. 
chological process. This activity consists in an expression of a thinker's reasons which commits her to them, rather than a report of those reasons. Success in the activity of reasoning constitutes being justified in holding a view, such that justification or rational entitlement is an achievement gained through the activity, and conferred on the basis of success at it, rather than some pre-existing psychological condition reported on in the activity.

A first benefit afforded by viewing reasoning as a normative activity rather than a psychological process is that it allows for the seamless integration of reasoning into the social practices of transacting reasons in argumentation. As Leite (p. 239) describes:

The basic point of the ordinary conversational activity of requesting and offering reasons in defense of beliefs is to provide a setting within which entitlements to hold beliefs can be challenged, defended, established, and shared. To develop a justification for one's belief is to attempt to establish or secure a positive normative status by offering reasons in one's defense, and successfully justifying a belief is more like achieving a checkmate than like showing or reporting that one has won a game.

Nor is this the only advantage of an activity-based account of the nature of reasoning.

Perhaps most importantly, viewing reasoning as an activity is a remarkably good fit with the basic idea of argumentative rationality according to which, to be rational is to base one's views on reasons by rightly responding to them. As Johnson (2000, p. 161) claims, "rationality can be understood as the disposition to, and the action of, using, giving, and-or acting on the basis of reasons." Similarly, in a pragmatic vein, Sbisà (2007, p. 94) proposes a Gricean-informed account of specifically argumentative rationality on which being rational involves that "we accept it as a task that we have to justify our moves [with reasons]" and draws upon Brandom's $(1994,2001)$ idea that being rational is to take part in the practice of conversational scorekeeping of commitments and entitlements. On these accounts, the activity of giving reasons occupies a central and essential, rather than peripheral and accidental, role in justification and rational entitlement. Additionally, to base one's views on reasons by rightly responding to them presupposes a normative, social practice by which reasons are transacted and the participation of rational agents in that practice.

Not only does an activity-based account of the nature of reasoning fit with the basic idea of argumentative rationality, it 
also accords well with the attendant assumptions identified in this paper. That reasoning is itself a normative activity satisfies the normativity assumption. It is a natural, indeed a paradigmatic, fit with the deontological assumptions of accountability, obligation, and voluntarism. It is a similarly natural fit with most of the structuralist and internalist assumptions, such as the rule, tracking, and articulable assumptions. Some assumptions, particularly the internalist assumption of accessibility and the structuralist assumption of basing, must be reconceived. On an expressivist view of giving reasons, accessabilist ideas that we are conscious of our reasons and can identify them upon reflection do not come with any connotation that these acts take the form of some introspective reporting of internal, psychological states. Similarly, the idea that our views are based on our reasons does not have a causal element, but instead a responsibilist one that speaks to our ability to accord our views to our reasons. Yet, these reinterpretations do not require any substantial adjustment to the overall picture of argumentative rationality. About the only assumption that is inconsistent with an activity-based account is the causal assumption - or at least the causal assumption spectatorially understood. In an important sense, our reasons are causally tied to our attitudes so long as we are rightly responding to reasons. Yet there is another sense in which the actual, psychological causes of our beliefs do not matter, so long as we are able to speak to our reasons and to make adjustments to our beliefs when we are unable to successfully defend them rationally.

As a final question, consider what I have called the "psychological adequacy" of the proposed view. How does the idea that reasoning is an activity relate to a dual-process account of the psychology of reasoning? While the two views clearly offer quite different accounts of the nature of reasoning, crucially they are not incompatible. Rather, they are talking about quite different things. Psychological accounts of reasoning describe the psychological states and processes that underlie the activity of reasoning. Yet, it is the activity which is the proper subject of rational assessment. Ultimately then, it need not matter whether a belief is produced, or caused, as the result of a system- 1 or a system-2 process. Instead what it at issue in the rational assessment at work in critical reasoning and argumentation is the subject's ability to provide cogent reasons for her beliefs and attitudes that demonstrate - rather than describe - her rational entitlement to them. 
Acknowledgements: An earlier version of this paper was presented to the 9th eColloq on argumentation, a live internet colloquium, on December 12, 2013. I extend my thanks to Frank Zenker for organizing the eColloq series and inviting the presentation, as well as the audience, especially Jean Goodwin, Michael Hoffman, Cate Hundleby, Marcin Lewinski, Dima Mohammed and Frank Zenker, for their instructive comments on the presented version of the paper and for their subsequent correspondence. Thanks are also due to the paper's anonymous referees and, especially, Hans Hansen and the editors of Informal Logic.

\section{References}

Aijaz, I., McKeown-Green, J., \& Webster, A. (2013). Burdens of proof and the case for unevenness. Argumentation, 27: 259-282.

Alston, W. (1989). Concepts of epistemic justification. In Epistemic justification: Essays in the theory of knowledge (pp. 81114). Ithaca: Cornell UP. [Reprinted from (1985). The Monist, 68: 57-89.]

Baron, J. (1985). Rationality and intelligence. Cambridge: Cambridge UP.

Biro, J. \& Siegel, H. (1992). Normativity, argumentation and epistemic theory of fallacies. In F.H. van Eemeren, R. Grootendorst, J.A. Blair \& C.A. Willard (Eds.), Argumentation illuminated (pp. 85-103). Amsterdam: SICSAT.

Biro, J. \& Siegel, H. (2006). Pragma-dialectic versus epistemic theories of arguing and arguments: Rivals or partners? In P. Houtlosser \& A. van Rees (Eds.), Considering pragmadialectics (pp. 1-10). Mahwah, NJ: Lawrence Erlbaum.

Brandom, R. (1994). Making it explicit. Cambridge, MA: Harvard UP.

Brandom, R. (2001). Articulating reasons: An introduction to inferentialism. Cambridge, MA: Harvard UP.

Brown, H. (1988). Rationality. London: Routledge.

Campolo, C. (2005). Treacherous ascents: On seeking common ground for conflict resolution. Informal Logic, 25: 37-50.

Chaiken, S. (1987). The heuristic model of persuasion. In M. Zanna, J.M. Olson \& C.P. Herman (Eds.), Social influence: The Ontario symposium (pp. 3-39). Hillsdale, NJ: Lawrence Erlbaum.

Corner, A. \& Hahn, U. (2013). Normative theories of argumentation: Are some norms better than others? Synthese, 190: 3579-3610.

(C) David Godden. Informal Logic, Vol. 35, No. 2 (2015), pp. 135-166. 
Eemeren, F.H. van \& Grootendorst, R. (2004). A systematic theory of argumentation: The pragma-dialectical approach. Cambridge: Cambridge UP.

Engel, P. (2000). Introduction: The varieties of belief and acceptance. In P. Engel (Ed.), Believing and accepting (pp. 130). Dordrecht: Kluwer.

Evans, J. St. B.T. (2002). Logic and human reasoning: An assessment of the deduction paradigm. Psychological Bulletin, 128: 978-996.

Evans, J. St. B.T. (2003). In two minds: Dual process accounts of reasoning. Tends in Cognitive Sciences, 7: 454-459.

Evans, J. St. B.T. (2004). History of the dual process theory of reasoning. In K. Manktelow \& M.C. Chung (Eds.), Psychology of reasoning: Theoretical and historical perspectives (pp. 241-266). Hove: Psychology Press.

Evans, J. St. B.T. (2008). Dual-processing accounts of reasoning, judgment, and social cognition. Annual Review of Psychology, 59: 255-278.

Evans, J. St. B.T. \& Frankish, K. (Eds.). (2009). In two minds: Dual processes and beyond. Oxford: Oxford UP.

Evans, J. St. B.T. \& Over, D.E. (1996). Rationality and reasoning. Hove: Psychology Press.

Frankish, K. \& Evans, J. St. B.T. (2009). The duality of mind: An historical perspective. In J. St. B.T. Evans \& K. Frankish (Eds.), In two minds: Dual processes and beyond (pp. 1-25). Oxford: Oxford UP.

Gigerenzer, G. (2000). Adaptive thinking: Rationality in the real world. Oxford: Oxford UP.

Gigerenzer, G. (2008). Rationality for mortals: How people cope with uncertainty. Oxford: Oxford UP.

Gigerenzer, G. \& Selten, R. (2001). Rethinking rationality. In G. Gigerenzer \& R. Selten (Eds.), Bounded rationality: The adaptive toolbox (pp. 1-12). Cambridge, MA: MIT Press.

Godden, D. (2010). The importance of belief in argumentation: Belief, commitment and the effective resolution of a difference of opinion. Synthese, 172: 397-414.

Godden, D. (2012). Rethinking the debriefing paradigm: The rationality of belief perseverance. Logos \& Episteme, 3: 5174.

Godden, D. (2014). Teaching rational entitlement and responsibility: A Socratic exercise. Informal Logic, Teaching Supplement, 34: 124-151.

Goldman, A. (1993). Philosophical applications of cognitive science. Boulder, CO: Westview Press. 
Govier, T. (1999). Rosebuds, judgement and critical thinking. In The philosophy of argument (pp. 123-136). Newport News, VA: Vale Press.

Habermas, J. (1981). The theory of communicative action. Vol. 1: Reason and the rationalization of society. ( $\mathrm{T}$. McCarthy, Trans.). Boston: Beacon Press.

Hahn, U. \& Oaskford, M. (2007). The rationality of informal argumentation: A Bayesian approach to reasoning fallacies. Psychological Review, 114: 704-732.

Harman, G. (1970). Knowledge, reasons, and causes. Journal of Philosophy, 67: 841-855.

Harman, G. (1986). Change in view: Principles of reasoning. Cambridge, MA: MIT Press.

Henle, M. (1962). On the relation between logic and thinking. Psychological Review, 69: 366-378.

Hume, D. ([1739] 1978). A treatise of human nature $\left(2^{\text {nd }}\right.$ ed.). (L.A. Shelby-Bigge \& P.H. Nidditch, Eds.). Oxford: Clarendon Press.

Hume, D. ([1777] 1975). Enquiries concerning human understanding and concerning the principles of morals ( $3^{\text {rd }} \mathrm{ed}$.). (L.A. Shelby-Bigge \& P.H. Nidditch, Eds.). Oxford: Clarendon Press.

Jäger, C. (2004). Epistemic deontology, doxastic voluntarism, and the principle of alternate possibilities. In W. Löffler \& P. Weingartner (Eds.), Knowledge and belief: Proceedings of the $26^{\text {th }}$ international Wittgenstein symposium (pp. 1-15). Wein, Switzerland. Available online at: http://www.abdn.ac.uk/philosophy/staff/documents/Epistemi cDeontologyFinalVersion.pdf (Accessed 15/4/2011.)

Johnson, R.H. (2000). Manifest rationality: A pragmatic theory of argument. Mahwah, NJ: Lawrence Erlbaum.

Korb, K. (2003). Bayesian informal logic and fallacy. Informal Logic, 23: 41-70.

Laden, A. (2012). Reasoning: A social picture. Oxford: Oxford UP.

Leite, A. (2004). On justifying and being justified. Philosophical Issues, Epistemology, 14: 219-253.

Locke, J. ([1690] 1975). Essay concerning human understanding. (P.H. Nidditch, Ed.). Oxford: Oxford UP.

Manktelow, K.I. \& Over, D.E. (1987). Reasoning and rationality. Mind \& Language, 2: 199-219.

Marcus, G. (2008). Kluge: The haphazard construction of the human mind. New York: Houghton Mifflin.

Melser, D. (2004). The act of thinking. Cambridge, MA: MIT Press.

(C) David Godden. Informal Logic, Vol. 35, No. 2 (2015), pp. 135-166. 
Oaksford, M. \& Chater, N. (2007). Bayesian rationality: The probabilistic approach to human reasoning. Oxford: Oxford UP.

Oaksford, M. \& Chater, N. (2009). Précis of Bayesian rationality: The probabilistic approach to human reasoning. Behavioral and Brain Sciences, 32: 69-84.

Oaksford, M., Chater, N., \& Hahn, U. (2008). Human reasoning and argumentation: A probabilistic approach. In J.E. Adler \& L.J. Rips (Eds.), Reasoning: Studies of inference and its foundations (pp. 383-413), Cambridge: Cambridge UP.

Osman, M. (2004). An evaluation of dual-process theories of reasoning. Psychonomic Bulletin and Review, 11, 988-1010.

O'Keefe, D.J. (1996). Argumentation studies and dual process models of persuasion. In J. Van Bentham, F.H. van Eemeren, R. Grootendorst \& R. Veltman (Eds.), Logic and argumentation (pp. 61-76). North-Holland: The Publishing House of the Royal Netherlands Academy.

Pelletier, F. \& Elio, R. (2005). The case for psychologism in default and inheritance reasoning, Synthese, 146: 7-35.

Petty, R.E. \& Cacioppo, J.T. (1986). Communication and persuasion: Central and peripheral routes to attitude change. New York: Springer-Verlag.

Pinto, R.C. (2001). Argument, inference and dialectic. Dordrecht: Kluwer.

Pinto, R.C. (2006). Evaluating inferences: The nature and role of warrants. Informal Logic, 26: 287-317.

Pinto, R.C. (2009). Argumentation and the force of reasons. Informal Logic, 29, 268-295.

Rescher, N. (1988). Rationality: A philosophical inquiry into the nature and rationale of reason. Oxford: Clarendon Press.

Rysiew, P. (2008). Rationality disputes: Psychology and epistemology. Philosophy Compass, 3: 1153-1176.

Sbisà, M. (2007). On argumentative rationality. Anthropology \& Philosophy, 8: 89-99.

Siegel, H. (1988). Educating reason: Rationality, critical thinking and education. New York: Routledge.

Siegel, H. (1997). Rationality redeemed: Further dialogues on an educational ideal. New York: Routledge.

Siegel, H. (2004). Rationality and judgment. Metaphilosophy, 35, 597-613.

Siegel, H. \& Biro, J. (1997). Epistemic normativity, argumentation and fallacies. Argumentation, 11: 277-292.

Siegel, H. \& Biro, J. (2008). Rationality, reasonableness, and critical rationalism: Problems with the pragma-dialectical view. Argumentation, 22: 191-203. 
Simon, H. (1957). A behavioral model of rational choice. In Models of man, social and rational: Mathematical essays on rational human behavior in a social setting. New York: Wiley.

Sloman, S. (1996). The empirical case for two systems of reasoning. Psychological Bulletin, 119: 3-22.

Stanovich, K. (1999). Who is rational? Studies of individual differences in reasoning. Mahwah, NJ: Lawrence Erlbaum.

Stein, E. (1996). Without good reason: The rationality debate in philosophy and cognitive science. Oxford: Oxford UP.

Stich, S. (1990). The fragmentation of reason. Cambridge, MA: MIT Press.

Strawson, P. (1962). Freedom and resentment. Proceedings of the British Academy, 48, 1-25. [Reprinted in (1994). J.M. Fischer \& M. Ravizza (Eds.), Perspectives on moral responsibility (pp. 45-66). Ithaca, NY: Cornell UP.]

Turner, D. \& Wright, L. (2005). Revisiting deep disagreement. Informal Logic, 25: 25-35.

Tversky, A. \& Kahneman, D. (1982). Judgements of and by representativeness. In D. Kahneman, P. Slovic \& A. Tversky (Eds.), Judgement under uncertainty: Heuristics and biases (pp. 84-98). New York: Cambridge UP.

Walton, D. (1996). Argumentation schemes for presumptive reasoning. Mahwah, NJ: Lawrence Erlbaum.

Walton, D. (2010). Why fallacies appear to be better arguments than they are. Informal Logic, 30: 159-184.

Wason, P.C. (1968). Reasoning about a rule. Quarterly Journal of Experimental Psychology, 20: 273-281.

Wason, P.C. \& Evans, J. St. B.T. (1975). Dual processes in reasoning? Cognition, 3: 141-154.

Willard, C.A. (1989). A theory of argumentation. Tuscaloosa: University of Alabama Press.

Williams, M. (2001). Problems of knowledge: A critical introduction to epistemology. Oxford: Oxford UP.

Zenker, F. (Ed.). (2013). Bayesian argumentation: The practical side of probability. Dordrecht: Springer.

(C) David Godden. Informal Logic, Vol. 35, No. 2 (2015), pp. 135-166. 